\title{
Virtual Screening of the Active Components of Garcinia mangostana Linn. Potentially Inhibiting the Interaction of Advanced Glycation End-products and their Receptor
}

\author{
Muhammad Ali Faisal ${ }^{1,2 *}$, Ika Kustiyah Oktaviyanti ${ }^{3}$, Hidayat Sujuti ${ }^{4}$, Achmad Rudijanto ${ }^{5}$ \\ ${ }^{1}$ Doctoral Program of Medical Science, Faculty of Medicine, Universitas Brawijaya, Malang, Indonesia; ${ }^{2}$ Department of \\ Ophthalmology, Faculty of Medicine, Lambung Mangkurat University, Banjarmasin, Indonesia; ${ }^{3}$ Department of Pathology \\ Anatomy, Faculty of Medicine, Lambung Mangkurat University, Banjarmasin, Indonesia; ${ }^{4}$ Department of Biochemistry, Faculty \\ of Medicine, Brawijaya University, Malang, Indonesia; ${ }^{5}$ Department of Internal Medicine, Faculty of Medicine, Brawijaya \\ University, Malang, Indonesia
}

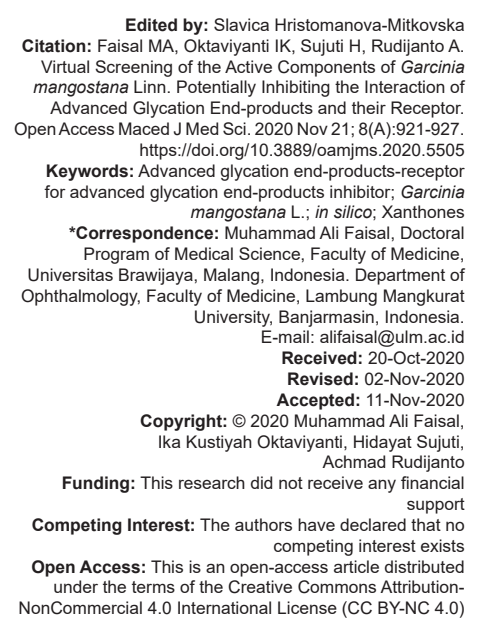

\begin{abstract}
BACKGROUND: Mangosteen (Garcinia mangostana L.) is a plant that contains various secondary metabolite compounds, one of which is xanthone. Xanthone in mangosteen has a variety of beneficial biological and medical effects, one of which is an antioxidative, anti-inflammatory, and antiapoptotic agent.

AIM: The aim of the study was to perform the selection of any xanthone in mangosteen pericarp that have potentially inhibit the interaction of AGEs and RAGE.

METHODS: The analysis was made in silico by docking method using software Hex 8.0. The docking was done between AGEs-RAGE, also between nine active compounds of $G$. mangostana with RAGE. The active compounds analyzed here were including $\alpha$-mangostin, $\beta$-mangostin, $\gamma$-mangostin, mangostanol, garcinone D, 1,6-Dihydroxy3,7-dimethoxy-2-(3-methylbut-2-enyl)-xanthone, gartanin, 1-isomangostin, and 3-isomangostin. Further analysis was performed to see the interactions formed between ligands with their receptors using software LigPlus + and Discovery Studio 4.1

RESULTS: 1-isomangostin, 3-isomangostin, $y$-mangostin, mangostanol, D-garcinone, and gartanin have potentially could inhibit the interaction and activity of imidazole in RAGE through a competitive binding mechanism.

CONCLUSIONS: The inhibition of imidazole-RAGE activity by the mangosteen active components may inhibit the
\end{abstract} pathobiology of AGEs-RAGE axis.

\section{Introduction}

The advanced glycation end-products receptor (RAGE) is a member of the immunoglobulin superfamily, described as an interaction site for AGEs on the cell surface. AGEs are the end product of the glycation process and the protein and lipid oxidation. The bond between AGE and RAGE can lead to oxidative stress and activation of a pro-inflammatory signaling pathway. AGEs consist of several very heterogeneous components, where their number will increase in patients with diabetes, kidney failure, Alzheimer's disease, and in the aging process. The formation of AGE consists of several processes; Maillard reactions are characterized by the formation of a brown substance produced from the non-enzymatic reaction of the reduction of sugars and amino acids on proteins [1], [2]. This reaction evolved from the bond between the amino group of proteins with the carbonyl group of sugars to form the Schiff bases and Amadori components, thus leading to the formation of various AGE derivatives [3], [4]. Some of the AGEs components include: $\mathrm{N}-\varepsilon$-(carboxymethyl) lysine $(\mathrm{CML})$ is one of the most widely accumulated protein-modified AGEs in the body of patients with diabetes and renal failure; argpyrimidine and imidazole are molecules derived from arginine products; and pentosidine is the cross-reaction product between the arginine-lysin residues [5], [6].

AGEs allegedly have an important role in the development of complications of diabetes, cardiovascular disease, stroke, and microvascular disease including retinopathy, neuropathy, nephropathy, and other complications [7], [8]. Several studies have reported that interactions between AGE and RAGE can activate signaling pathways such as ERK1/ERK2 kinase and $N F-\kappa B$ [9], [10], thus regulating cellular function associated with the expression of various pro-inflammatory and 
pro-thrombotic genes which are important in the pathogenesis of various chronic diseases [11], [12].

Garcinia mangostana L. (Guttiferae) or commonly known as mangosteen is a tropical plant originating from India, Myanmar, Malaysia, Philippines, Sri Lanka, and Thailand. The pericarp part of the mangosteen fruit has been widely used in medicine for the treatment of infections and skin injuries, dysentery, diarrhea, and anti-inflammation. Mangosteen plants are known to contain various secondary metabolite compounds, one of which is xanthones. The number of xanthone compounds successfully isolated from the mangosteen pericarp is approximately 50 species. The first xanthone isolated is then named as mangostin. The main medical and biological properties of G. mangostana are as antioxidant, anti-tumor, anti-inflammatory, antiallergic, anti-bacterial, anti-fungal, anti-malarial, and anti-viral compounds [13]. In this study, we will analyze the potential inhibition of AGE-RAGE activity by some of the active components of mangosteen, including $\alpha$-mangostin, $\beta$-mangostin, $\gamma$-mangostin, mangostanol, garcinone D, 1,6-Dihydroxy-3,7-dimethoxy-2-(3methylbut-2-enyl)-xanthone, gartanin, 1-isomangostin, and 3-isomangostin. This study will be conducted through a computational analysis and 3D protein structure analysis. This study is important as one of the earliest screening methods in determining which the mangosteen active components have potential as a therapeutic agent against pathological RAGE in diabetes. Crude ethanol extract of G. mangostana pericarp potentially showed antioxidant, anti-glycation, DDIT3 inhibitor, and anti-apoptotic activity in goat cultured lenses [14].

\section{Materials and Methods}

\section{Search for sequences of the amino acid and active component structure of $G$. mangostana}

The sequences of amino acids that make up the RAGE protein (GI: 2497319) were obtained from the National Center for Biotechnology Information (NCBI), United States National Library of Medicine, National Institute of Health (http://www.ncbi.nlm.nih. gov) database. The 3D structure of the active compound components of G. mangostana and AGE components was obtained from PubChem Open Chemistry Database. There are nine active compounds, including $\alpha$-mangostin (CID: 5281650), $\beta$-mangostin (CID: 5495925), mangostanol (CID: 10048103), garcinone D (CID: 5495926), 1,6-Dihydroxy-3,7-dimethoxy2-(3-methylbut-2-enyl)-xanthone (CID: 5316764), gartanin (CID: 5281633), $\gamma$-mangostin (CID: 5464078), 1-isomangostin (5281641), and 3-isomangostin (13873655). In addition, there are four AGE compounds including CML (CID: 123 800), argpyrimidine (CID:
17750123), imidazole (CID: 795), and pentosidine (CID: 119593). The 3D structures of the active components of G. mangostana and AGE were obtained in the form of *.sdf file format, which will then be converted to *.pdb files using OpenBabel software [15].

\section{Protein 3D structure modeling}

The 3D structure modeling of RAGE was predicted using SWISS-MODEL webserver by homology modeling method [16], [17]. The 3D structure of the protein was then validated by the Ramachandran plot analysis.

\section{Docking and visualization between proteins-ligands}

Simulation of docking between AGE-RAGE as well as between the active components of $G$. mangostana L. with RAGE was performed using HEX 8.0 software [18]. The docking protocol consists of three stages of visualization, namely, rigid body energy minimization, semi-flexible repair, and finishing refinement in explicit solvent. Docking results were then visualized with Chimera 1.6.2 and Discovery Studio 4.1 software.

\section{Analysis of binding interactions between proteins and ligands}

The results of the next docking analysis will be visualized using Discovery Studio 4.1, LigPlot+ [19] and LigandScout 3.1 [20] software. An interaction between proteins and ligands was analyzed to see the amount and type of bonds formed, such as hydrogen bonds, hydrophobic bonds, and Van der Waals bonds. Pharmacophore analysis was also performed to see the residues directly involved in the interaction process, as well as the minimization energy analysis to improve the structure and shape of the molecule during the interaction.

\section{Results}

\section{The interaction between AGEs and RAGE}

It appears that all AGEs bind to the Ig-like C2-type 1 domain of RAGE (Figure 1a). The possible interaction between AGEs (CML, pentosidine, argpyrimidine, and imidazole) with RAGE is shown in Figure $1 \mathrm{~b}$. The CML compound binds to RAGE through six hydrogen bonds and four hydrophobic bonds on Gly121, Lys122, Pro123, Glu124, Val126, Val144, Ser145, and Glu146 residues of RAGE (Table 1). The total binding energy required to allow the formation of the interaction is $-244.26 \mathrm{~kJ} / \mathrm{mol}$. 


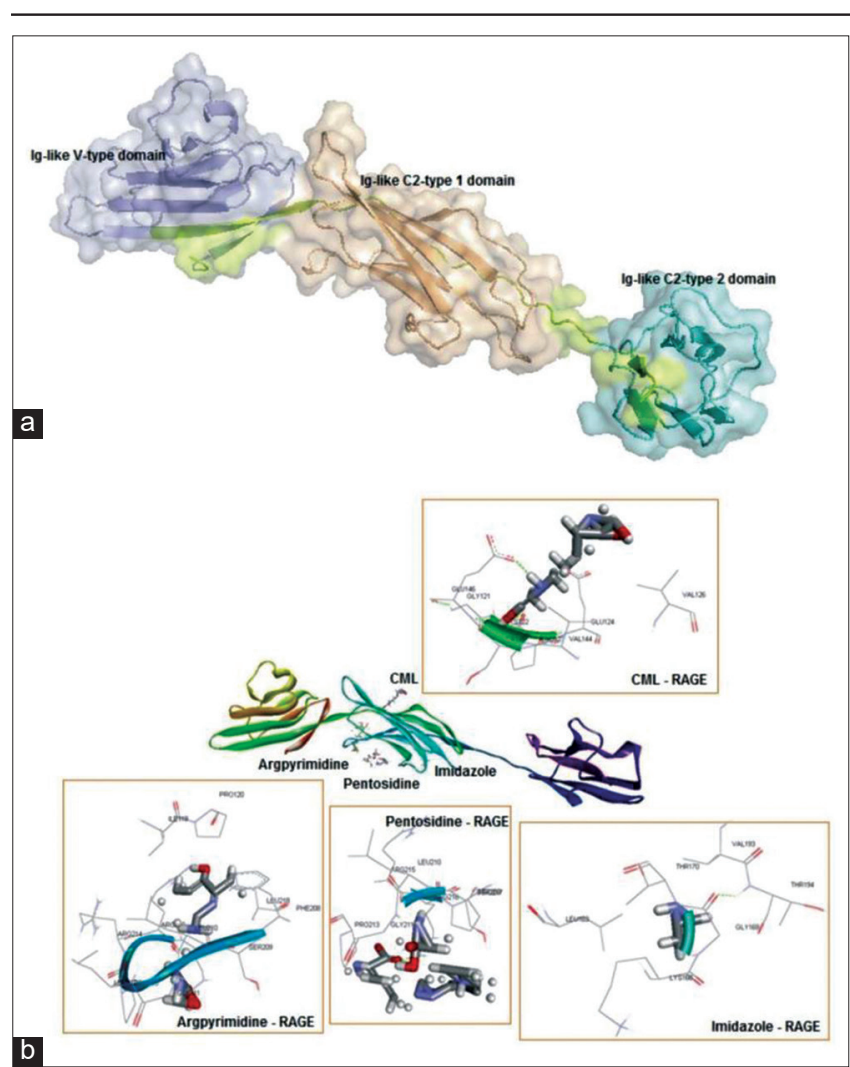

Figure 1: (a) Ig-like C2-type 1 domain of advanced glycation endproducts receptor (RAGE). (b) Possible interactions between RAGE and four types of AGEs; carboxymethyllysine, argpyrimidine, pentosidine, and imidazole

The pentosidine compound binds to RAGE by two hydrogen bonds and one hydrophobic bond in the Ser209 and Arg216 amino acid residues, where the binding energy required for the interaction is lower than the energy required for CML interaction with RAGE, that is, $-289.56 \mathrm{~kJ} / \mathrm{mol}$. In the interaction between the argpyrimidine compound and RAGE, no hydrogen bonds were formed at all, but seven hydrophobic interactions with the amino acids Ser290, Pro213, Arg214, Leu210, Gly211, Leu212, and Arg215 were formed. The total binding energy required for the interaction is -225.25 $\mathrm{kJ} / \mathrm{mol}$, which is greater when compared with the energy required by $\mathrm{CML}$ and pentosidine to bind to RAGE. The imidazole compound requires the greatest energy to bind to RAGE when compared with the other AGEs of $-97.22 \mathrm{~kJ} / \mathrm{mol}$, where this interaction formed six hydrophobic bonds with the amino acids Leu163, Lys168, Gly169, Thr170, Val193, and Thr194.

\section{Possible interactions between the active components of $G$. mangostana with RAGE}

To examine the possible ability of the active components of $G$. mangostana to inhibitAGE activity, it is necessary to analyze the docking between components of the active compound ( $\alpha$-mangostin, $\beta$-mangostin, mangostanol, garcinone D, 1,6-Dihydroxy-3,7dimethoxy-2-(3-methylbut-2-enyl)-xanthone, gartanin, $\gamma$-mangostin, 1-isomangostin, and 3-isomangostin) and RAGE. Visualization and analysis of docking interactions showed that of nine active compounds of G. mangostana, six of them are suspected to have the ability to inhibit the interaction between the imidazole and RAGE, which is known through competitive binding between the active components of $G$. mangostana and imidazole to bind to RAGE (Figure 1b). Six compounds include 1-isomangostin, 3-isomangostin, $\gamma$-mangostin, mangostanol, D-garcinone, and gartanin (Figure 2).

The binding energy required by the active components of G. mangostana to bind to RAGE is much smaller than the energy required by imidazole to interact. Binding energy required by the active components of 1-isomangostin, 3-isomangostin, $\gamma$-mangostin, mangostanol, D-garcinone, and gartanin is $-262.49 \mathrm{~kJ} / \mathrm{mol},-256.47 \mathrm{~kJ} / \mathrm{mol},-262.87 \mathrm{~kJ} / \mathrm{mol}$, $-255.87 \mathrm{~kJ} / \mathrm{mol},-253.14 \mathrm{~kJ} / \mathrm{mol}$, and $-253.24 \mathrm{~kJ} / \mathrm{mol}$, respectively. Amino acids directly involved in the interaction process are completely listed in Table 2 . Interaction analysis results showed that 1 -isomangostin compound

Table 1: AGEs and RAGE interactions

\begin{tabular}{|c|c|c|c|c|c|}
\hline Molecule & Point interaction & Category & Atomic donor & Acceptor atom & Binding energy \\
\hline \multirow[t]{10}{*}{ CML-RAGE } & GLU146: H -: CML: O & Hydrogen bond & A: GLU146: H & CML: O & $-244.26 \mathrm{~kJ} / \mathrm{mol}$ \\
\hline & CML: O - GLY121: O & Hydrogen bond & CML: O & GLY121: O & \\
\hline & CML: H - GLU146: OE2 & Hydrogen bond & CML: H & GLU146: OE2 & \\
\hline & CML: H - GLY121: O & Hydrogen bond & CML: H & GLY121: O & \\
\hline & CML: H - GLU124: OE2 & Hydrogen bond & CML: H & GLU124: OE2 & \\
\hline & CML: H - VAL144: O & Hydrogen bond & CML: H & VAL144: O & \\
\hline & CML: H - VAL126: O & Hydrophobic bond & CML: H & VAL126: O & \\
\hline & CML: H - PRO123: O & Hydrophobic bond & CML: H & PRO123: O & \\
\hline & CML: H - SER145: O & Hydrophobic bond & CML: H & SER145: O & \\
\hline & CML: H - LYS122: O & Hydrophobic bond & CML: H & LYS122: O & \\
\hline \multirow[t]{3}{*}{ Pentosidine-RAGE } & ARG216: HH21 - Pentosidine: O & Hydrogen bond & ARG216: HH21 & Pentosidine: $\mathrm{O}$ & $-289.56 \mathrm{~kJ} / \mathrm{mol}$ \\
\hline & ARG216: HH22 - Pentosidine: O & Hydrogen bond & ARG216: HH22 & Pentosidine: 0 & \\
\hline & Pentosidine: H-SER209: O & Hydrophobic bond & Pentosidine: $\mathrm{H}$ & SER209: O & \\
\hline \multirow[t]{7}{*}{ Argpyrimidine-RAGE } & Argpyrimidine: H - SER209: O & Hydrophobic bond & Argpyrimidine: $\mathrm{H}$ & SER209: O & $-225.25 \mathrm{~kJ} / \mathrm{mol}$ \\
\hline & Argpyrimidine: H - PRO213: O & Hydrophobic bond & Argpyrimidine: $\mathrm{H}$ & PRO213: 0 & \\
\hline & Argpyrimidine: H - ARG214: O & Hydrophobic bond & Argpyrimidine: $\mathrm{H}$ & ARG214: O & \\
\hline & Argpyrimidine: H - LEU210: O & Hydrophobic bond & Argpyrimidine: $\mathrm{H}$ & LEU210: O & \\
\hline & Argpyrimidine: H - GLY211: O & Hydrophobic bond & Argpyrimidine: $\mathrm{H}$ & GLY211: O & \\
\hline & Argpyrimidine: $\mathrm{H}$ - ARG215: O & Hydrophobic bond & Argpyrimidine: $\mathrm{H}$ & ARG215: O & \\
\hline & Argpyrimidine: H - LEU212: O & Hydrophobic bond & Argpyrimidine: $\mathrm{H}$ & LEU212: O & \\
\hline \multirow{6}{*}{ Imidazole-RAGE } & Imidazole: H - LYS168: O & Hydrophobic bond & Imidazole: $\mathrm{H}$ & LYS168: O & $-97.22 \mathrm{~kJ} / \mathrm{mol}$ \\
\hline & Imidazole: H - THR170: O & Hydrophobic bond & Imidazole: H & THR170: O & \\
\hline & Imidazole: H - VAL193: O & Hydrophobic bond & Imidazole: $\mathrm{H}$ & VAL193: O & \\
\hline & Imidazole: H - LEU163: O & Hydrophobic bond & Imidazole: H & LEU163: O & \\
\hline & Imidazole: H - GLY169: O & Hydrophobic bond & Imidazole: H & GLY169: O & \\
\hline & Imidazole: H - THR194: O & Hydrophobic bond & Imidazole: H & THR194: O & \\
\hline
\end{tabular}


had competitive binding with imidazole on the amino acid residues of Leu163 and Val193; 3-isomangostin compounds on amino acid residues of Leu163, Lys168, Gly169, and Thr170; $\gamma$-mangostin compounds on the amino acid residues of Leu163, Lys168, Gly169, Val193, and Thr194; mangostanol compounds on amino acid residues of Leu163, Lys168, Gly169, Thr170, and Val193; D-garcinone compound on the amino acid residue of Leu163, Gly169, Thr170, Val193, and Thr194; and gartanin compounds on amino acid residues of Gly169, Val193, and Thr194.

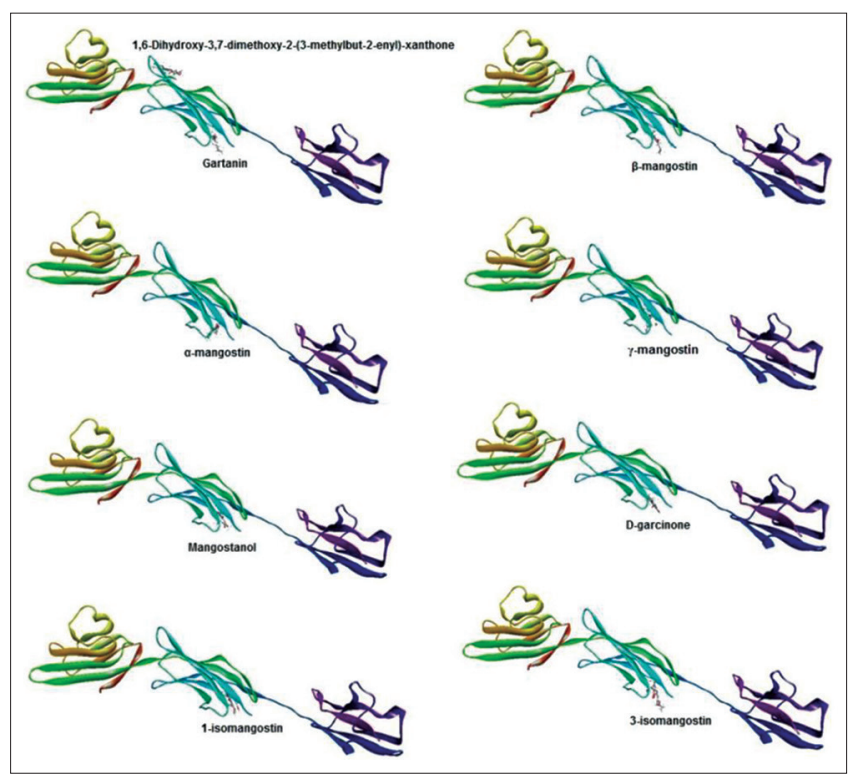

Figure 2: Possible interaction between advanced glycation endproducts and nine active components of Garcinia mangostana $L$.

Interactions site of the six active components of $G$. mangostana with RAGE is located in the lg-like C2-type 1 domain of the RAGE extracellular domain. Lower binding energy required by active components of G. mangostana to bind to RAGE when compared with imidazole compounds, as well as the similarity of interactions site between the components, suggests that the compounds of 1-isomangostin, 3-isomangostin, $\gamma$-mangostin, mangostanol, D-garcinone, and gartanin have potential to inhibit the interaction between AGEs (especially imidazole) and RAGE.

\section{Discussion}

The RAGE consists of three domains, the extracellular domain, transmembrane domain, and cytoplasmic domain. The extracellular domain itself is composed of Ig-like V-type domains, Ig-like C2-type 1 domains, and Ig-like C2-type 2 domain. The cytoplasmic domain is the C-terminal part required in the transduction signal mechanism in the cell [20]. Based on the results of UNIPROT analysis (uniprot. org), the amino acid sequence of the RAGE domains starts with a signal recognition sequence consisting of 22 amino acids, which is then followed by an extracellular domain with a length of 319 amino acids, consisting of three domains: Ig-like V-type domain (amino acid residue No. 23-109), Ig-like C2-type 1 domain (amino acid no. 123-219), and Ig-like C2-type 2 domain (amino acid no. 233-315). The transmembrane domain is composed of 21 helix-shaped amino acids starting from amino acid numbers 342-362, while the cytoplasmic domain is composed of 40 amino acids which start from number 363-402 [21].

Results of this study reported that the many bonds formed between AGEs and RAGE are hydrogen bonds with hydrophobic bonds. The electrostatic attraction between polar molecules in the hydrogen bonds occurs when the hydrogen atom $(\mathrm{H})$ binds to atoms having high electronegative properties such as nitrogen $(\mathrm{N})$ or oxygen $(\mathrm{O})$. The hydrogen bond is one of the strong bonds $(5-30 \mathrm{~kJ} / \mathrm{mol})$, in which the hydrogen bonds are known to be stronger than Van der Waals and hydrophobic interactions [22]. This study also showed that all AGEs will bind to RAGE in the Ig-like C2-type 1 domain, so it is suspected that this domain plays an important role in supporting the negative effects of AGE in the pathogenesis of diabetes and various other complications. Certain AGE compounds such as argpyrimidine and imidazole associated with their bond with RAGE are thought to play awfully essential role in increasing the complications of diabetes and chronic inflammatory diseases. Both the compounds when binding to RAGE can induce cellular transduction signal dysfunction through increased oxidative stress, as well as the synthesis and secretion of pro-inflammatory cytokines [23], [24].

G. mangostana L. has been widely known to contain various secondary metabolites such as prenylated and oxygenated xanthones [25]. Xanthones or xanthen-9H-ones are secondary metabolites found in some high-level plant families, fungi, and lichen [26], in which there is an important class of oxygenated heterocycles. Several types of xanthones present in mangosteen are including $\alpha-, \beta-$, and $\gamma$-mangostin [27], [28], garcinone D [29], mangostanol [30], 1-isomangostin, 3-isomangostin [31], 1,6-Dihydroxy-3,7-dimethoxy-2-(3-methylbut-2-enyl)xanthone, and gartanin [32]. The xanthone compounds present in mangosteen have various beneficial cellular activities, including antioxidant compounds, anti-inflammatory, anti-allergic, anti-bacterial, antifungal, and many others [13]. Of the nine compounds of xanthones analyzed in this study, six of them are thought to inhibit AGE-RAGE activity through a competitive binding mechanism. The compounds include 1-isomangostin, 3-isomangostin, $\gamma$-mangostin, mangostanol, D-garcinone, and gartanin. Presumably through its ability to inhibit the interaction between AGE and RAGE, these compounds may play a role in inhibiting the pathogenesis of various inflammatory diseases. 
Table 2: Active components of Garcinia mangostana and RAGE interaction

\begin{tabular}{|c|c|c|c|c|c|}
\hline Molecule & Point interaction & Category & Atomic donor & Acceptor atom & Binding energy \\
\hline 1,6-Dihydroxy-3,7-dimethoxy-2-(3- & 1,6 dihydroxy:O - LYS122:O & Hydrophobic bond & 1,6 dihydroxy:O & LYS122: O & $-234.36 \mathrm{~kJ} / \mathrm{mol}$ \\
\hline \multirow[t]{5}{*}{ methylbut-2-enyl)-xanthone } & 1,6 dihydroxy:O - GLY121:O & Hydrophobic bond & 1,6 dihydroxy: 0 & GLY121: O & \\
\hline & 1,6 dihydroxy:O - PRO120:O & Hydrophobic bond & 1,6 dihydroxy:0 & PRO120: O & \\
\hline & 1,6 dihydroxy:O - LEU184:O & Hydrophobic bond & 1,6 dihydroxy:O & LEU184: O & \\
\hline & 1,6 dihydroxy:O - GLY147:O & Hydrophobic bond & 1,6 dihydroxy:O & GLY147: O & \\
\hline & 1,6 dihydroxy:O - GLU146:O & Hydrophobic bond & 1,6 dihydroxy: 0 & GLU146: O & \\
\hline \multirow[t]{6}{*}{ 1-isomangostin-RAGE } & 1-isomangostin: O - VAL140: O & Hydrophobic bond & 1-isomangostin: $\mathrm{O}$ & VAL140: O & $-262.49 \mathrm{~kJ} / \mathrm{mol}$ \\
\hline & 1-isomangostin: O - TYR204:O & Hydrophobic bond & 1-isomangostin: 0 & TYR204: O & \\
\hline & 1-isomangostin:O - PRO202:O & Hydrophobic bond & 1-isomangostin: $O$ & PRO202: O & \\
\hline & 1-isomangostin:O - PRO195:O & Hydrophobic bond & 1-isomangostin: $O$ & PRO195:O & \\
\hline & 1-isomangostin:O - LEU163:O & Hydrophobic bond & 1-isomangostin: $O$ & LEU163:O & \\
\hline & 1-isomangostin:O - VAL193:O & Hydrophobic bond & 1-isomangostin: $O$ & VAL193:0 & \\
\hline \multirow[t]{4}{*}{ 3-isomangostin-RAGE } & 3-isomangostin:H - THR170:O & Hydrophobic bond & 3-isomangostin: $\mathrm{H}$ & THR170:O & $-256.47 \mathrm{~kJ} / \mathrm{mol}$ \\
\hline & 3-isomangostin:H - GLY169:O & Hydrophobic bond & 3-isomangostin: $\mathrm{H}$ & GLY169:O & \\
\hline & 3-isomangostin:O - LYS168:O & Hydrophobic bond & 3-isomangostin: 0 & LYS168:O & \\
\hline & 3-isomangostin:O - LEU163:O & Hydrophobic bond & 3-isomangostin: $\mathrm{O}$ & LEU163:0 & \\
\hline \multirow[t]{4}{*}{ a-mangostin-RAGE } & a-mangostin:O - GLY199:O & Hydrogen bond & $\alpha$-mangostin: $O$ & GLY199:O & $-260.42 \mathrm{~kJ} / \mathrm{mol}$ \\
\hline & a-mangostin:O - THR200:O & Hydrophobic bond & a-mangostin:O & THR200:O & \\
\hline & a-mangostin:O - THR201:O & Hydrophobic bond & $\alpha$-mangostin: $\mathrm{O}$ & THR201:O & \\
\hline & a-mangostin:C - PRO202:O & Hydrophobic bond & $\alpha$-mangostin:C & PRO202:C & \\
\hline \multirow[t]{3}{*}{$\beta$-mangostin-RAGE } & $\beta$-mangostin:O - THR201:O & Hydrogen bond & $\beta$-mangostin:O & THR201:O & $-266.73 \mathrm{~kJ} / \mathrm{mol}$ \\
\hline & B-mangostin:C - GLY198:O & Hydrophobic bond & $\beta$-mangostin:C & GLY198:O & \\
\hline & $\beta$-mangostin:C - GLY199:O & Hydrophobic bond & $\beta$-mangostin:C & GLY199:O & \\
\hline \multirow[t]{5}{*}{ Mangostanol-RAGE } & Mangostanol:C - LYS168:O & Hydrophobic bond & Mangostanol:C & LYS168:O & $-255.87 \mathrm{~kJ} / \mathrm{mol}$ \\
\hline & Mangostanol:O - LEU163:O & Hydrophobic bond & Mangostanol:O & LEU163:O & \\
\hline & Mangostanol:C - GLY169:O & Hydrophobic bond & Mangostanol:C & GLY169:O & \\
\hline & Mangostanol:C - VAL193:O & Hydrophobic bond & Mangostanol:C & VAL193:O & \\
\hline & Mangostanol:C - THR170:O & Hydrophobic bond & Mangostanol:C & THR170:O & \\
\hline \multirow[t]{13}{*}{ Y-mangostin-RAGE } & y-mangostin:O - PRO225:O & Hydrogen bond & $y$-mangostin:O & PRO225:O & $-262.87 \mathrm{~kJ} / \mathrm{mol}$ \\
\hline & y-mangostin:O - TYR204:O & Hydrophobic bond & $y$-mangostin: $O$ & TYR204:O & \\
\hline & y-mangostin:O - LEU191:O & Hydrophobic bond & $y$-mangostin:O & LEU191:O & \\
\hline & y-mangostin:O - LEU163:O & Hydrophobic bond & $y$-mangostin:O & LEU163:O & \\
\hline & Y-mangostin:O - VAL193:O & Hydrophobic bond & y-mangostin:O & VAL193:O & \\
\hline & y-mangostin:O - GLY169:O & Hydrophobic bond & $y$-mangostin:O & GLY169:O & \\
\hline & y-mangostin:O - THR170:O & Hydrophobic bond & $y$-mangostin:O & THR170:O & \\
\hline & Y-mangostin:O - LYS168:O & Hydrophobic bond & y-mangostin:O & LYS168:O & \\
\hline & y-mangostin:O - THR194:O & Hydrophobic bond & $y$-mangostin:O & THR194:O & \\
\hline & y-mangostin:O - PRO195:O & Hydrophobic bond & $y$-mangostin:O & PRO:195:O & \\
\hline & y-mangostin:O - PRO202:O & Hydrophobic bond & $\mathrm{y}$-mangostin: $\mathrm{O}$ & PRO202:O & \\
\hline & Y-mangostin:O - LEU132:O & Hydrophobic bond & $Y$-mangostin:O & LEU132:0 & \\
\hline & y-mangostin:O - TYR204:O & Hydrophobic bond & $y$-mangostin:O & TYR204:O & \\
\hline \multirow[t]{13}{*}{ D-garcinone-RAGE } & D-garcinone:H -THR194:O & Hydrogen bond & D-garcinone:H & THR194:O & $-253.14 \mathrm{~kJ} / \mathrm{mol}$ \\
\hline & D-garcinone:H -ASP159:O & Hydrophobic bond & D-garcinone:H & ASP159:O & \\
\hline & D-garcinone:H -THR201:O & Hydrophobic bond & D-garcinone:H & THR201:O & \\
\hline & D-garcinone:H -LEU158:O & Hydrophobic bond & D-garcinone:H & LEU158:O & \\
\hline & D-garcinone:H -GLY198:O & Hydrophobic bond & D-garcinone:H & GLY198:O & \\
\hline & D-garcinone:O -GLY199:O & Hydrophobic bond & D-garcinone:O & GLY199:O & \\
\hline & D-garcinone:O -ALA196:O & Hydrophobic bond & D-garcinone:O & ALA196:O & \\
\hline & D-garcinone:O -PRO195:O & Hydrophobic bond & D-garcinone:O & PRO195:O & \\
\hline & D-garcinone:O -PRO202:O & Hydrophobic bond & D-garcinone:O & PRO202:O & \\
\hline & D-garcinone:O -GLY169:O & Hydrophobic bond & D-garcinone:O & GLY169:O & \\
\hline & D-garcinone:O -VAL193:O & Hydrophobic bond & D-garcinone:O & VAL193:O & \\
\hline & D-garcinone:O -LEU163:O & Hydrophobic bond & D-garcinone:O & LEU163:O & \\
\hline & D-garcinone:O -THR170:O & Hydrophobic bond & D-garcinone:O & THR170:O & \\
\hline \multirow[t]{8}{*}{ Gartanin-RAGE } & Gartanin: H - THR194:O & Hydrogen bond & Gartanin: $\mathrm{H}$ & THR194:O & $-253.24 \mathrm{~kJ} / \mathrm{mol}$ \\
\hline & Gartanin: H - GLY169:O & Hydrophobic bond & Gartanin: H & GLY169:O & \\
\hline & Gartanin: H - ALA196:O & Hydrophobic bond & Gartanin: $\mathrm{H}$ & ALA196:O & \\
\hline & Gartanin: H - GLY198:O & Hydrophobic bond & Gartanin: H & GLY198:O & \\
\hline & Gartanin: H - PRO202:O & Hydrophobic bond & Gartanin: H & PRO202:O & \\
\hline & Gartanin: H - LEU158:O & Hydrophobic bond & Gartanin: H & LEU158:O & \\
\hline & Gartanin: H - PRO195:O & Hydrophobic bond & Gartanin: H & PRO195:O & \\
\hline & Gartanin: H - VAL193:O & Hydrophobic bond & Gartanin: H & VAL193:O & \\
\hline \multirow[t]{5}{*}{ Mangostanol-RAGE } & Mangostanol:C - LYS168:O & Hydrophobic bond & Mangostanol:C & LYS168:O & $-255.87 \mathrm{~kJ} / \mathrm{mol}$ \\
\hline & Mangostanol:O - LEU163:O & Hydrophobic bond & Mangostanol:O & LEU163:O & \\
\hline & Mangostanol:C - GLY169:O & Hydrophobic bond & Mangostanol:C & GLY169:O & \\
\hline & Mangostanol:C - VAL193:O & Hydrophobic bond & Mangostanol:C & VAL193:O & \\
\hline & Mangostanol:C - THR170:O & Hydrophobic bond & Mangostanol:C & THR170:O & \\
\hline
\end{tabular}

$\gamma$-mangostin isolated from the pericarp of mangosteen fruit had inhibitor activity in the $\mathrm{PGE}_{2}$ secretory process. In addition to inhibiting the conversion of arachidonic acid to PGE2, the $\gamma$-mangostin compound may also inhibit the activity of cyclooxygenase- 1 and -2 (COX-1 and COX-2) enzymes [33].

Binding energy constitutes the energy required to allow the bonding between the ligand and the receptor, the lower the required energy the stronger and more stable the bonds formed. Conversely, if the energy required for bonding is greater, it will cause instability and difficulty in the bonding between receptor and ligand. In this study, the binding energy for AGEs and RAGE varies widely. Of some compounds of AGEs (CML, pentosidine, argpyrimidine, and imidazole), the compound having the lowest binding energy is pentosidine $\Sigma$ : $-289.56 \mathrm{~kJ} / \mathrm{mol}$, while the compound having the highest binding energy is imidazole $\Sigma$ : $-97.22 \mathrm{~kJ} / \mathrm{mol}$. Imidazole is an organic component of the formula $\mathrm{C} 3 \mathrm{H} 4 \mathrm{~N} 2$ classified in the alkaloids class. Although the derivatives of imidazole are known to have some pharmacological activities such as antidepression, anti-viral, and anti-cancer [34], the presence of this compound which is one of the AGEs in some pathological conditions such as diabetic cataract and diabetic retinopathy is expected not to have beneficial effect so that the inhibition of activity of this compound 
is thought to prevent the occurrence of complications caused by the interaction of this compound and its receptor, RAGE.

\section{Conclusions}

The six xanthones, namely, 1-isomangostin, 3-isomangostin, $\gamma$-mangostin, mangostanol, D-garcinone, and gartanin potentially could inhibit the interaction and activity of imidazole in RAGE through a competitive binding mechanism. In this case, the inhibition of imidazole-RAGE activity by the mangosteen active components may inhibit the pathobiology of the AGERAGE axis.

\section{References}

1. Akbar IZ, Permatasari N, Soeatmadji DW, Kalim H. Reactive oxygen species and cell morphology of MC3T3E1 preosteoblast cell line exposed to methylgyoxal by laser scanning confocal microscopy. Oxid Antioxid Med Sci. 2013;2(1):65-8. https://doi. org/10.5455/oams.050313.br.006

2. Ramasamy R, Vannucci SJ, Yan SS, Herold K, Yan SF, Schmidt AM. Advanced glycation end products and RAGE: A common thread in aging, diabetes, neurodegeneration, and inflammation. Glycobiology. 2005;15(7):16-28. https://doi. org/10.1093/glycob/cwi053

PMid:15764591

3. Avery NC, Bailey AJ. The effects of the Maillard reaction on the physical properties and cell interactions of collagen. Pathol Biol. 2006;54(7):387-95. https://doi.org/10.1016/j.patbio.2006.07.005 PMid: 16962252

4. Yamamoto $\mathrm{H}$, Watanabe T, Yamamoto Y, Yonekura H, Munesue $\mathrm{S}$, Harashima A, et al. RAGE in diabetic nephropathy. Curr Mol Med. 2007;7(8):752-7. https://doi.org/10.2174/156652407783220769 PMid: 18331233

5. Guglielmotto M, Aragno M, Tamagno E, Vercellinatto I, Visentin S, Medana C, et al. AGEs/RAGE complex upregulates BACE1 via NF-кB pathway activation. Neurobiol Aging. 2012;33(1):13-27. https://doi.org/10.1016/j.neurobiolaging.2010.05.026 PMid:20638753

6. Sitkiewicz E, Tarnowski K, Poznański J, Kulma M, Dadlez M. Oligomerization interface of RAGE receptor revealed by MS-monitored hydrogen deuterium exchange. PLoS One. 2013;8(10):e76353. https://doi.org/10.1371/journal.pone.0076353 PMid:24098480

7. Win MT, Yamamoto Y, Munesue S, Saito H, Han D, Motoyoshi S, et al. Regulation of RAGE for attenuating progression of diabetic vascular complications. Exp Diabetes Res. 2012;2012:894605. https://doi.org/10.1155/2012/894605

PMid:22110482

8. Basta G, Schmidt AM, De Caterina R. Advanced glycation end products and vascular inflammation. Implications for accelerated atherosclerosis in diabetes. Cardiovasc Res. 2004;63(4):58292. https://doi.org/10.1016/j.cardiores.2004.05.001 PMid:15306213
9. Yan SD, Schmidt AM, Anderson GM, Zhang J, Brett J, Zou YS, et al. Enhanced cellular oxidant stress by the interaction of advanced glycation end products with their receptors/binding proteins. J Biol Chem. 1994;269:9889-97.

PMid:8144582

10. Lander HL, Tauras JM, Ogiste JS, Hori O, Moss RA Schmidt AM. Activation of the receptor for advanced glycation end products triggers a p21 ${ }^{\text {ras }}$-dependent mitogen-activated protein kinase pathway regulated by oxidant stress. J Biol Chem. 1997;272(28):17810-4. https://doi.org/10.1074/jbc.272.28.17810 PMid:9211935

11. Owen WF Jr., Hou FF, Stuart RO, Kay J, Boyce J, Chertow GM et al. $\beta 2$-microglobulin modified with advanced glycation end products modulates collagen synthesis by human fibroblasts. Kidney Int. 1998;53(5):1365-73. https://doi. org/10.1046/j.1523-1755.1998.00882.x

PMid:9573554

12. Park L, Raman KG, Lee KJ, Yan L, Ferran LJ Jr., Chow WS et al. Suppression of accelerated diabetic atherosclerosis by the soluble receptor for advanced glycation end products. Nat Med. 1998;4(9):1025-31. https://doi.org/10.1038/2012 PMid:9734395

13. Ovale-Magallanes B, Eugenio-Perez D, Pedraza-Chaverri J. Medicinal properties of mangosteen (Garcinia mangostana L): A comprehensive update. Food Chem Toxicol. 2017;109(1):10222. https://doi.org/10.1016/j.fct.2017.08.021 PMid:28842267

14. Faisal MA, Octavianty IK, Sujuti $H$, Rudijanto A. Anticataract Activity of Ethanolic Extract of Garcinia Mangostana Linn. Pericarp on Glucose Induced Cataractogenesis in Goat Lens. Open Access Maced J Med Sci. 2020;8:571-7. https://doi. org/10.3889/oamjms.2020.4792

15. O'Boyle N, Banck M, James CA, Morley C, Vandermeersch T, Hutchison GR. Open Babel: An open chemical toolbox. J Cheminform. 2011;3:33. https://doi.org/10.1186/1758-2946-3-33 PMid:21982300

16. Arnold K, Bordoli L, Kopp J, Schwede T. The SWISS-MODEL workspace: A web-based environment for protein structure homology modelling. Bioinformatics. 2006;22(2):195-201. https://doi.org/10.1093/bioinformatics/bti770 PMid:16301204

17. Kiefer F, Arnold K, Kunzli M, Bordoli L, Schwede T. The SWISS MODEL repository and associated resources. Nucleic Acids Res. 2009;37:387-92. https://doi.org/10.1093/nar/gkn750 PMid:18931379

18. Macindoe G, Mavridis L, Venkatraman V, Devignes MD, Ritchie DW. HexServer: An FFT-based protein docking server powered by graphics processors. Nucl Acids Res. 2010;38:4459. https://doi.org/10.1093/nar/gkq311 PMid:20444869

19. Laskowski RA, Swindells MB. LigPlot+: Multiple ligand-protein interaction diagrams for drug discovery. J Chem Inf Model. 2011;51(10):2778-86. https://doi.org/10.1021/ci200227u PMid:21919503

20. Wolber G, Langer T. LigandScout: 3-D pharmacophores derived from protein-bound ligands and their use as virtual screening filters. J Chem Inf Model. 2005;45(1):160-9. https://doi. org/10.1021/ci049885e

PMid: 15667141

21. Xie J, Mendez JD, Mendez-Valenzuela V, AguilarHernandez MM. Cellular signalling of the receptor for advanced glycation end products (RAGE). Cell Signal. 2013;25(11):218597. https://doi.org/10.1016/j.cellsig.2013.06.013

PMid:23838007 
22. Arunan E, Desiraju GR, Klein RA, Sadlej J, Scheiner S, Alkorta I, et al. Definition of the hydrogen bond (IUPAC recommendations 2011). Pure Appl Chem. 2011;83(8):1637-41. https://doi. org/10.1351/pac-rec-10-01-02

23. Xue J, Rai V, Frolov S, Singer D, Chabierski S, Xie J, et al. Advanced glycation end product (AGE) recognition by the receptor for AGEs (RAGE). Structure. 2011;19(5):722-32. https://doi.org/10.1016/j.str.2011.02.013

\section{PMid:21565706}

24. Jandeleit-Dahm K, Watson A, Soro-Paavonen A. The AGE/ RAGE axis in diabetes-accelerated atherosclerosis. Clin Exp Pharmacol Physiol. 2008;35(3):329-34. https://doi. org/10.1111/j.1440-1681.2007.04875.x PMid:18290873

25. Peres $\mathrm{V}$, Nagem TJ, de Oliveira FF. Tetraoxygenated naturally occurring xanthones. Phytochemistry. 2000;55(7):683-710. https://doi.org/10.1016/s0031-9422(00)00303-4

PMid:11190384

26. Vieira LM, Kijjoa A. Naturally-occurring xanthones: Recent developments. Curr Med Chem. 2005;12(21):2413-46. https:// doi.org/10.2174/092986705774370682

PMid:16250871

27. Schmid W. Ueber das mangostin. Liebigs Ann Chem. 1855;93(1):83-9. https://doi.org/10.1002/jlac.18550930105

28. Jefferson $A Q$, Scheimann $F$, Sim KY. Isolation of $\gamma$-mangostin from Garcinia mangostana and preparation of the natural mangostins by selective demethylation. Aust $\mathrm{J}$ Chem. 1970;23:2539-43. https://doi.org/10.1071/ch9702539

29. Sen AK, Sarkar KK, Majumder PC, Banerji N. Garcinone-D, a new xanthone from Garcinia mangostane Linn. Indian J Chem. 1986;25B:1157-8.

30. Chairungsrilerd N, Takeuchi K, Ohizumi Y, Nozoe S, Ohta T. Mangostanol, a prenyl xanthone from Garcinia mangostana. Phytochemistry. 1996;43(5):1099-102. https://doi.org/10.1016/ s0031-9422(96)00410-4

31. Mahabusarakam W, Wiriyachtra P, Taylor W. Chemical constituents of Garcinia mangostana. J Nat Prod. 1987;50(3):474-8. https://doi.org/10.1021/np50051a021

32. Asai $F$, linuma $M$, Tanaka $T$, Tosa $H$. A xanthone from pericarps of Garcinia mangostana. Phytochemistry. 1995;39:943-4. https://doi.org/10.1016/0031-9422(95)00042-6

33. Nakatani $\mathrm{K}$, Nakahata N, Arakawa $\mathrm{T}$, Yasuda $\mathrm{H}$, Ohizumi $\mathrm{Y}$ Inhibition of cyclooxygenase and prostaglandin E2 syntesis by c-mangostin, a xanthone derivative in mangosteen, in $\mathrm{C} 6$ rat glioma cells. Biochem Pharmacol. 2002;63(1):73-9. https://doi. org/10.1016/s0006-2952(01)00810-3 PMid:11754876

34. Shalini K, Sharma PK, Kumar N. Imidazole and its biological activities: A review. Chem Sin. 2010;1(3):36-47. Available from: https://www.imedpub.com/articles/imidazole-and-its-biologicalactivities-a-review.pdf. 